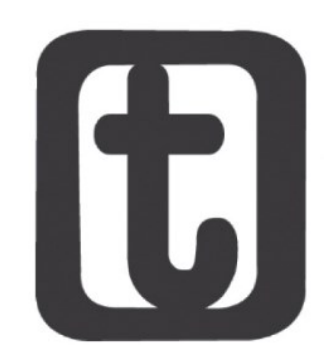

\title{
A FORMAÇÃO EM SERVIÇO SOCIAL NO PERÍODO NEODESENVOLVIMENTISTA DE DILMA ROUSSEFF: OS ENTRAVES PARA UMA EDUCAÇÃO EMANCIPADORA
}

\author{
Professional Formation in Social Work in Dilma Rousseff's Neodevelopmentist period: \\ Hindrances for a Emancipatory Education
}

\author{
Suellen Bezerra Alves Keller*
}

\begin{abstract}
RESUMO
O presente artigo busca tematizar a configuração da formação em Serviço Social entre os anos de 2011 e 2016 , período em que o Brasil foi governado pela presidenta Dilma Rousseff e momento em que se vivenciou o esgotamento do projeto neodesenvolvimentista. A partir de um estudo qualitativo, em que foi realizada pesquisa teórico-bibliográfica com base no método materialista-dialético, investigou-se como a educação institucionalizada, no modo de produção capitalista, cumpre a função prática de formar para o mercado, e ideológica de criar consensos sobre as massas. Ao final dos governos de coalizão petistas, o Serviço Social vivenciou muitos desafios, resultantes, sobretudo, do crescimento de cursos de graduação à distância. Conclui-se que o enfrentamento do conservadorismo na profissão e na realidade social prescinde de uma formação emancipadora, que proporcione conhecimento crítico sobre a totalidade e permita a construção de estratégias efetivas de atuação.
\end{abstract}

\section{PALAVRAS-CHAVE}

Formação Profissional. Serviço Social. Esgotamento do Neodesenvolvimentismo.

\section{ABSTRACT}

The present article seeks to outline the configuration of Social Work formation between the years 2011 and 2016, a period in which Brazil was governed by President Dilma Rousseff and the time when the depletion of the neodevelopmental project was experienced. From a qualitative study in which a theoretical-bibliographic research was carried out based on the materialistic-dialectical method, it was investigated how institutionalized education, in the capitalist mode of production, fulfills the practical function of forming for the market, and ideological of create consensus on the masses. At the end of the PT coalition governments, Social Work experienced many challenges, mainly resulting from the growth of undergraduate distance courses. It is concluded that the confrontation of conservatism in the profession and in the social reality demand with an emancipatory formation that provides critical knowledge about the totality and allows the construction of effective strategies of action.

\section{KEYWORDS}

Professional Formation. Social Work. Exhaustion of Neodevelopmentism.

Submissão: 30/5/2018.

Aceite: 2/12/2018.

\footnotetext{
* Assistente Social. Mestra em Serviço Social. Doutoranda em Serviço Social pela Pontifícia Universidade Católica do Rio Grande do Sul (PUCRS). Assistente Social Judiciária do Tribunal de Justiça do Estado do Rio Grande do Sul (TJRS). Av. Borges de Medeiros, 1565, CEP.: 90110-906, Porto Alegre (RS). E-mail: <suellenbezerra@live.com>.
}

DOI 10.22422/temporalis.2018v18n36p336-348 


\section{tempordilis}

\section{INTRODUÇÃO}

A compreensão de como o assistente social intervém na realidade implica examinar a sua formação, cuja prática é orientada a partir de uma visão de mundo que é também engendrada na academia. Romper a aparência dos fenômenos sociais é um caminho balizado pelas diretrizes que regem os conteúdos tidos como fundamentais para o exercício da profissão, contribuindo para o alinhamento político, ético, teórico, metodológico e instrumental da sua atuação.

Desvendar como se dá a formação profissional em Serviço Social no período entre 2011 e 2016 é o objetivo geral do presente artigo. Como metodologia, utilizou-se da pesquisa teórico-bibliográfica, assentada em uma concepção teórico-metodológica de análise fundada no materialismo dialético ${ }^{1}$. Parte-se da premissa de que, no Serviço Social brasileiro, a atuação profissional assume uma especifidade de acordo com o momento histórico, resultando em formações muito distintas de acordo com a materialidade posta. Em sua origem, com um viés confessional, os assistentes sociais eram demandados pela Igreja, Estado e empresariado a responderem as contradições de classe, no surgimento da sociedade industrial brasileira, pautados por uma ideologia determinada pelos interesses desta tríade (IAMAMOTO; CARVALHO, 2007).

Ao longo da sua trajetória histórica, a profissão foi negando e modificando seus fundamentos iniciais, ao passo que, através da sua relação com a conjuntura, foi se afastando do projeto político conservador. Desde a década de 1970, o Serviço Social, ao se alicerçar teoricamente na tradição marxista, vem tentando promover uma atuação profissional alinhada com lutas e resistências àqueles que exercem a dominação social.

A formação de assistentes sociais foi caracterizada pelos consensos e embates que a profissão travou com os projetos políticos hegemônicos na esfera da governabilidade. A construção de um projeto profissional alinhado com as demandas da classe trabalhadora é recente e vem sendo tensionado constantemente diante do avanço do conservadorismo na sociedade brasileira. Por isso, a existência de uma direção política crítica, bem como de diretrizes curriculares em consonância com esse projeto, não garante que a formação de assistentes sociais no Brasil tenha a mesma conformação.

Estando o Brasil em um período de incertezas, é adequado se pensar que a formação de assistentes sociais permanece em constante conflito com os interesses das classes dominantes. O esgotamento do projeto neodesenvolvimentista ${ }^{2}$ coloca em questão quais desafios irão surgir para o Serviço Social nessa nova conjuntura.

\footnotetext{
${ }^{1}$ Esse artigo é fruto de parte da pesquisa realizada na tese de doutoramento da pesquisadora, intitulada $\mathrm{A}$ Ascensão do Conservadorismo e o Esgotamento do Projeto Neodesenvolvimentista: Implicações Profissionais ao Serviço Social. A tese foi produzida no Programa de Pós-Graduação em Serviço Social da Pontifícia Universidade Católica do Rio Grande do Sul (PUCRS), nos anos entre 2015 e 2019, com apoio da Coordenação de Aperfeiçoamento de Pessoal de Nível Superior (CAPES).

2 Neodesenvolvimentismo, para Boito Júnior. (2018) constitui-se na proposta de retomada do desenvolvimento em países da América Latina, após o esgotamento do projeto neoliberal e a crise gerada pelo aumento do desemprego, da miséria e da concentração de renda. Foi essa proposta que deu sustentação à política de crescimento econômico e transferência de renda levada a efeito nos governos Lula e Dilma. Na mesma esteira, Giovanni Alves (2014) entende que o neodesenvolvimentismo pode ser compreendido na qualidade de um modelo de desenvolvimento capitalista, comprometido em estabelecer
} 
A discussão será ordenada em três partes: primeiro, será abordada a função ideológica da educação no capitalismo contemporâneo; depois, se apresentará o quadro da educação superior entre os anos 2011 e 2016, período em que o Brasil foi governado pela presidenta Dilma Rousseff, momento em que se vivenciou o esgotamento do projeto neodesenvolvimentista; e, por fim, será evidenciada a relação entre o quadro político e a configuração da formação de assistentes sociais nesse período.

\section{A função ideológica da educação formal no capitalismo}

Qual a funcionalidade da educação formal no sistema capitalista? Esse questionamento remete, primeiramente, a definição do que se entende pelo próprio conceito de educação, tendo em vista que a partir de distintas perspectivas, ela pode expressar a possibilidade (ou não) da reprodução das formas de dominação social.

No Dicionário Crítico da Educação, Souza (2014) alerta para o fato do termo educação ser amplamente usado no senso comum de forma generalizada, muitas vezes, remetendo ao conceito de escolarização, diante da centralidade da instituição escola na tarefa de formar gerações. Contudo, para o autor, ao se falar de educação, o que a distinguiria de outras práticas sociais seria a intencionalidade da ação, pois ela é sempre "[...] orientada por um valor (econômico, político, sociocultural, ético e estético) assumido como relevante em cada sociedade, seja para conservar uma dada realidade, seja para transformá-la" (SOUZA, 2014, p. 78).

Os valores, conhecimentos e habilidades que disputam hegemonia na sociedade brasileira contemporânea são permeados pelo quadro de profunda desigualdade social, que embora tenha sido redesenhado nos governos petistas, se mantém distante de uma redistribuição profunda de riquezas ${ }^{3}$. Encontra-se na educação superior um instrumento essencial para se legitimar relações de dominação, na medida em que não se oportuniza enquanto um direito social universal, ofertando-se, no mais das vezes, um ensino disciplinador e de conformação dos sujeitos à ordem vigente.

O ensino tem uma importante funcionalidade para reprodução da lógica do capital tanto no nível material quanto ideológico. No plano material, busca-se a educação superior formal muito mais como mecanismo de ascensão social do que como um processo de formação que possibilitará aquisição de conhecimentos sobre a realidade. Acessar o ensino superior, o que é possível apenas para uma parcela minoritária da sociedade, significa ter maiores possibilidades de competitividade e acesso ao mercado formal de trabalho, bem como de poder auferir uma renda superior.

Dados do Censo da Educação Superior do Instituto Nacional de Estudos e Pesquisas Educacionais Anísio Teixeira (INEP) revelam que, no ano de 2014, no Brasil, existiam 3.205.001,00 (CONSELHO FEDERAL DE SERVIÇO SOCIAL/CONSELHO REGIONAL DE

\footnotetext{
um novo patamar de acumulação de capital, tendo o Estado o papel de redistribuir renda ao mesmo tempo em que amplia o mercado de consumo, garantindo suportes mínimos de existência à classe trabalhadora mais pobre.

${ }^{3} \mathrm{O}$ Brasil é $\mathrm{o} 10^{\circ}$ país mais desigual do mundo e o $4^{\circ}$ da América Latina, conforme o Ranking do Índice de Gini (PIRES, 2017).
} 


\section{tempordilis}

SERVIÇO SOCIAL, 2012b) alunos matriculados na educação superior, o que corresponde a apenas 1,55\% da população brasileira naquele mesmo ano (total de 206,1 milhões). Conforme o relatório da Organização para Cooperação e Desenvolvimento Econômico (OCDE) (INSTITUTO NACIONAL DE ESTUDOS E PESQUISAS EDUCACIONAIS, 2015), no Brasil, quem possui um diploma de nível superior tem uma renda de aproximadamente $152 \%$ a mais do que aqueles que possuem somente um diploma de ensino médio. Tais dados revelam que o acesso a formação profissional, além de um privilégio em termos de acesso, é uma estratégia buscada como meio de ascender socialmente e auferir maior renda.

No que diz respeito ao plano ideológico, a educação cumpre a função central de reprodução da ideologia dominante em pelo menos dois elementos. O primeiro deles é disseminar a aceitação da lógica do mercado, inclusive de receber uma formação voltada à aquisição das competências exigidas por ele, como comprova o apelo das escolas de ensino médio e cursinhos preparatórios para os vestibulares, inteiramente voltados para a aprovação nos cursos mais concorridos - entenda-se, profissões que melhor remuneram. Um segundo aspecto toca a disseminação do ideal social do consumo que, através da mídia e da indústria cultural (ADORNO; HORKHEIMER, 2006), disseminam promessas de felicidade vinculadas à aquisição de bens materiais.

As poucas possibilidades de reflexão crítica são constantemente minadas no campo da educação formal, a exemplo da recente reforma do ensino médio (BRASIL, 2016), em que o Ministério da Educação (MEC) publicizou um primeiro texto que apontava o fim da obrigatoriedade das aulas de artes, educação física, filosofia e sociologia no currículo do Ensino Médio, tendo voltado atrás após grande repercussão social (MEC..., 2016). Sobre a influência ideológica da educação formal, Mészáros (2008) afirma:

A educação institucionalizada [..] serviu [...] ao propósito de não só fornecer o conhecimento e o pessoal necessário à máquina produtiva em expansão do sistema do capital, como também gerar e transmitir um quadro de valores que legitima os interesses dominantes [...] (MÉSZÁROS, 2008, p. 35).

Tal propósito educacional consegue ser atingido na medida em que se formam intelectuais no seio das classes dominantes, que trabalharão para a racionalização e a legitimação da ordem social vigente, tida como um dado naturalizado e inalterável. Quando esta intervenção dos intelectuais não gera o consenso, o Estado reproduz a disciplina através da coerção. Gramsci (1995), ao definir a função política e cultural exercida pelos intelectuais no bloco histórico ${ }^{4}$, afirma que:

A relação entre os intelectuais e o mundo da produção não é imediata, como é o caso nos grupos sociais fundamentais, mas é 'mediatizada', em diversos graus, por todo o contexto social, pelo conjunto das superestruturas, do qual os intelectuais são precisamente 'funcionários'. [...] Os intelectuais são os 'comissários' do grupo dominante para o exercício das funções subalternas da hegemonia social e do governo político, isto é: 1) do consenso ‘espontâneo' dado

\footnotetext{
${ }^{4} \mathrm{O}$ conceito de bloco histórico em Gramsci remete ao estudo das relações entre estrutura e superestrutura, definidas a partir da existência de uma historicidade concreta, composta por uma estrutura, formada por classes sociais condicionadas pelas relações de forças produtivas, e por uma superestrutura ideológica e política, sendo os intelectuais os agentes sociais responsáveis, no âmbito da superestrutura, pela vinculação orgânica entre esses dois elementos.
} 
pelas grandes massas da população à orientação impressa pelo grupo fundamental dominante à vida social, consenso que nasce 'historicamente' do prestígio (e, portanto, da confiança) que o grupo dominante obtém, por causa de sua posição e de sua função no mundo da produção; 2) do aparato de coerção estatal que assegura 'legalmente' a disciplina dos grupos que não 'consentem' nem ativa nem passivamente, mas que é constituído para toda a sociedade, na previsão dos momentos de crise no comando e na direção, nos quais fracassa o consenso espontâneo (GRAMSCI, 1995, p. 10-11).

Dessa forma, o exercício da função intelectual passa a cumprir, em relação com os grupos sociais fundamentais (dominantes ou dominados), a tarefa histórica de travar disputas ideológicas. A escola, nesse cenário, seria o instrumento utilizado para elaborar os intelectuais de diversos níveis (GRAMSCI, 1995) e seria utilizada como espaço de constituição da hegemonia intelectual de uma classe sobre outra.

O modo de produção capitalista tende a reduzir a educação a um mero instrumento de dominação ideológica, bem como de formar para reproduzir papéis sociais existentes. Passa ao largo dessa visão que o ensino quando alinhado a uma perspectiva crítica, de totalidade social, pode servir como mecanismo de emancipação. Emancipação que não se restringe ao seu sentido político, que significa a "[...] redução do homem, por um lado, a membro da sociedade burguesa, a indivíduo egoísta independente, e, por outro, a cidadão, a pessoa moral [...]” (MARX, 2010, p. 54), mas a emancipação humana, que estará plenamente realizada quando:

[...] o homem individual real tiver recuperado para si o cidadão abstrato e se tornado ente genérico na qualidade de homem individual na sua vida empírica, no seu trabalho individual, nas suas relações individuais, quando o homem tiver reconhecido e organizado suas "forces propres" [forças próprias] como forças sociais e, em consequência, não mais separar de si mesmo a força social na forma da força política (MARX, 2010, p. 54).

Assim, existe uma outra possibilidade no âmbito da educação, com vistas à construção de vias emancipatórias. Por ser espaço de contradições, na escola também reside a capacidade de construção da transformação social. Meszáros defende que, felizmente, o processo de aprendizagem não se situa apenas no plano formal, mas a maioria das nossas experiências de educação estão presentes nas outras dimensões da vida em sociedade. Para ele,

[...] o papel da educação é soberano, tanto para elaboração de estratégias apropriadas e adequadas para mudar as condições objetivas de reprodução, como para a automudança consciente dos indivíduos chamados a concretizar a criação de uma ordem social metabólica radicalmente diferente (MÉSZÁROS, 2008, p. 65).

Como a educação ocorre em diversos planos, não apenas no formal, as demais esferas da vida social podem despertar o senso crítico necessário à transformação societária. Observa-se, na materialidade da vida social, o engajamento de diversas subjetividades que lutam para a concretização de pautas emancipatórias. Portanto, por mais que o capital sufoque o potencial de mudança da educação, as contradições inerentes a esse estágio de desenvolvimento econômico não conseguem suprimir por completo as resistências que se manifestam também no processo de ensino-aprendizagem. 
No contexto de esgotamento do projeto neodesenvolvimentista, a educação, sobretudo a educação superior, se viu em um momento de contradições, ao passo que se ampliavam as oportunidades de acesso, mas este era caracterizado pela flexibilização, aligeiramento e desqualificação. Ainda assim, resistências se fizeram presentes nos espaços para além da educação formal, inclusive na dimensão político-organizativa da profissão do Serviço Social.

\section{O esgotamento do projeto neodesenvolvimentista e a educação superior em Serviço Social no Brasil}

A agenda social levada a cabo pela governabilidade petista começou a apresentar indícios de falência ainda no primeiro mandato da presidenta Dilma Rousseff, especialmente após as Manifestações de Junho de 2013. Como aponta Avritzer (2016), os protestos de Junho de 2013 abriram espaço para movimentos conservadores, os quais impulsionaram diretamente o impeachment da presidenta.

O quadro de crise do Governo Dilma se firmou diante de, pelo menos, três fatores: primeiramente, do processo de desaceleração econômica; ainda, da dificuldade de diálogo com os outros Poderes; e, como estopim, da onda de protestos que inicialmente teve como pauta central a resistência ao aumento das tarifas de transporte público, mas que se tornou um grande aglomerado de reivindicações que iam desde críticas aos gastos com a Copa do Mundo, até discursos sobre os investimentos em serviços públicos e contra a corrupção política. Este último fator foi decisivo para a queda de popularidade da presidenta caísse drasticamente 5 .

Em 2015, após a reeleição, a crise se manteve quando grupos como o Movimento Brasil Livre, Vem pra Rua e Revoltados Online (que se autodenominaram como apartidários, mas receberam apoio de partidos como DEM, PSDB e PMDB (LOPES; SEGALLA, 2016) ${ }^{6}$ ) convocaram, através das redes sociais, protestos solicitando o impeachment da presidenta e em defesa da Operação Lava Jato, que tem investigado políticos envolvidos em esquemas de corrupção.

A aceitação do processo de impeachment pelo então presidente da Câmara dos Deputados Eduardo Cunha (FONSECA; DIONÍSIO; KANIAK, 2017) se deu ainda em dezembro do mesmo ano, sendo que a presidenta foi acusada de crime de responsabilidade por realizar as chamadas pedaladas fiscais, ou seja, abertura de crédito suplementar. O processo foi encerrado em agosto de 2016, tendo como resultado a cassação do mandato de Dilma.

Apesar de todo o processo ter se realizado dentro da legalidade formal, foi possível identificar, gradativamente, que ocorreu no Brasil, de fato, foi um verdadeiro golpe de Estado. Não um golpe nos moldes tradicionais, com uso da força, mas através de outros órgãos do Estado, como o afirma Freixo e Rodrigues (2016), quando referem que o governo petista foi derrubado pela articulação jurídica, técnica e política entre setores do Poder

\footnotetext{
${ }^{5}$ Em artigo do jornal Folha de São Paulo, é apresentada pesquisa Datafolha com dados que revelam que a aprovação do governo Dilma caiu de 57\% de aprovação no início de junho de 2013, antes da onda de protestos, para 30\% ao final do mesmo mês. Disponível em: <http://www1.folha.uol.com.br/poder/2013/06/1303541popularidade-de-dilma-cai-27-pontos-apos-protestos.shtml>. Acesso em: 05 jun. 2017.

${ }^{6}$ Site de notícias UOL teve acesso a gravação que revela ligação do MBL com partidos políticos.
} 


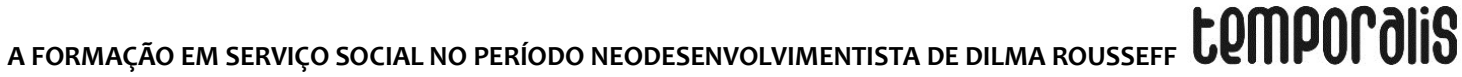

Judiciário e forças políticas conservadoras do Parlamento, ficando as Forças Armadas em uma posição de aparente neutralidade.

A construção de narrativas acerca do fato político, se foi ou não golpe, balizou o embate ao longo dos anos de 2016 e 2017. Ainda que do ponto de vista formal todos os procedimentos foram seguidos, e isso justificaria a legalidade do impeachment, os fatores reais que confluíram para a derrubada de Dilma não foi o que lhe imputaram, qual seja, crime de responsabilidade pela abertura de crédito suplementar. O próprio voto dos congressistas comprova a assertiva ora levantada, tendo em vista que se mencionava a corrupção, crise econômica, desemprego, anti-petismo etc., quase nada abordando o mérito do julgamento, que seria as ditas pedaladas.

Não obstante o projeto político neodesenvolvimentista de conciliação entre crescimento econômico e investimento social tenha sido interrompido precocemente pelo impeachment, durante os governos de Dilma, a educação apresentou momentos de avanços e outros de retrocessos. Logo no início do seu primeiro mandato, Dilma criou o Programa Nacional de Acesso ao Ensino Técnico e ao Emprego (Pronatec), Lei 12.513, de 26 de outubro de 2011, que pretendia gerar vagas em cursos de formação técnica e profissional, destinados a estudantes do ensino médio e trabalhadores, em alternativa ao ensino superior.

As medidas tomadas em relação à educação superior são um dos traços centrais do projeto neodesenvolvimentista. Sob o pretexto de democratizar o acesso ao ensino, relegou-se para segundo plano a ampliação em vagas de universidades públicas, atuando o Estado como indutor no incremento de número de vagas, no entanto, na esfera privada. A manutenção do Programa Universidade para Todos (PROUNI), bem como o aprimoramento do Fundo de Financiamento Estudantil (FIES), mesmo que de imediato aumentem o número de pessoas matriculadas em ensino superior, garantem as vagas pela via concorrencial do mercado, mantendo uma histórica contradição: as universidades públicas são ocupadas por segmentos sociais que, a rigor, dela não precisariam, enquanto a classe trabalhadora precisa comprar o direito à educação.

Como o ensino superior formal é um mecanismo de ascensão social dentro da ótica do capitalismo, as políticas levadas a efeito nesse âmbito corroboram para uma visão de conciliação de classe. Por um lado, a iniciativa privada é privilegiada à medida que se desenvolve com a disponibilidade de recursos públicos, por outro, o aluno realiza o desejo de ascender ao ensino superior, que potencialmente irá lhe garantir uma melhor remuneração da sua força de trabalho.

Durante o período de vigência do governo Dilma, o Serviço Social travou importantes embates na defesa do ensino superior qualificado e de uma formação profissional que permita o desenvolvimento de competências para além das necessidades do mercado. A conciliação de interesses promovida impulsionou debates interior no Serviço Social, tendo em vista que esse modelo de educação teve um forte avanço sobre a profissão.

Seguindo a caminhada de lutas contra a precarização e mercantilização da educação superior, já em 2011, o conjunto formado pelo Conselho Federal de Serviço Social e Conselhos Regionais de Serviço Social (conjunto CFESS-CRESS) em parceria com a 


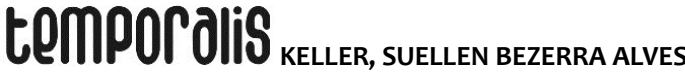

Executiva Nacional de Estudantes de Serviço Social (ENESSO) e com a Associação Brasileira de Ensino e Pesquisa em Serviço Social (ABEPSS) reeditaram o relatório Sobre a incompatibilidade entre graduação à distância e Serviço Social. Este documento teve a sua primeira edição publicada em novembro de 2010, elaborado pelo Grupo de Trabalho e Formação Profissional, formado por representantes das entidades representativas, apresentando dados e informações que retratavam a situação dos cursos de graduação à distância ofertados em todo o Brasil.

O segundo volume do documento, publicado no ano de 2014, apresentou informações acerca do descompromisso das instituições de ensino, bem como do Estado com a educação superior. O texto denunciava a mercantilização do ensino na medida em que se dissemina o discurso de "[...] democratização do ensino [...]" (CONSELHO FEDERAI DE SERVIÇO SOCIAL-CONSELHOS REGIONAIS DE SERVIÇO SOCIAL, 2012b, 2014, 2015), tendo em vista que a garantia do direito social passa a ser obtida pela via concorrencial do mercado.

As críticas em torno do ensino à distância foram a tônica do período, buscando evidenciar que essa é uma estratégia de expansão dos negócios educacionais com fins à lucratividade a partir da redução de custos, quando não se demandam muitos recursos para seu funcionamento. Pautou-se, ainda, as dificuldades de se formar Assistentes Sociais, profissionais com a exigência de uma formação teórico-metodológica consistente, em cursos à distância que carecem de recursos humanos, físicos, didáticos e pedagógicos. Como exemplo, concreto das mudanças no quadro profissional, Lewgoy e Maciel (2017) apontam que em 2011 o CFESS divulgou que o número de alunos superou o de profissionais regulares, pela primeira vez na história da profissão.

A campanha mais provocativa e polêmica sobre ensino EAD foi a Educação não é fast-food (CONSELHO FEDERAL DE SERVIÇO SOCIAL, 2011), que, após grande repercussão, foi acusada de excludente e discriminatória em relação aos participantes de tal modalidade (estudantes e tutores). A campanha chegou a ser proibida por determinação judicial, tendo a categoria se posicionado contra a censura, explicitando que a contrariedade a essa modalidade de ensino tem como fundamento a crítica à lógica expansionista da educação, a qual serve para reforçar as desigualdades sociais e não para ampliar o acesso democrático ao ensino?.

lamamoto (2007) já alertava para as consequências do crescimento exponencial de vagas nos cursos de Serviço Social, que são majoritariamente ofertadas pela iniciativa privada. A autora (2007) refere que o crescimento do contingente profissional a curto prazo repercute no crescimento acelerado do desemprego, na precarização das condições de trabalho e na redução salarial, como resultado da criação de um exército assistencial de reserva, que busca a formação como um recurso de qualificação do voluntariado.

Diante da massificação da formação em Serviço Social nesse período, a categoria profissional se vê ameaçada pela reação conservadora tanto no âmbito acadêmico quanto

\footnotetext{
${ }^{7}$ A contra-argumentação da categoria sobre a censura encontra-se no CFESS Manifesta - Educação não é fastfood: Diga não para a graduação à distância em Serviço Social, datado de 25 de maio de 2011 (CONSELHO FEDERAL DE SERVIÇO SOCIAL, 2011).
} 


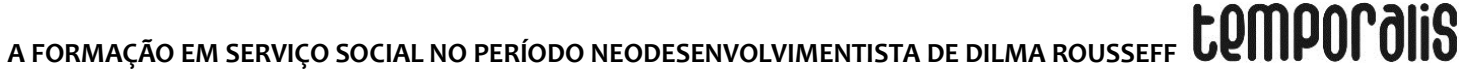

profissional. Os desafios para a materialização de uma formação profissional crítica se coloca em todos as modalidades e naturezas de ensino, em maior ou menor grau. Ainda assim, maiores desafios são postos quando a construção do conhecimento é mediada por aparatos tecnológicos e através de processos individuais de ensino-aprendizagem.

Concomitante a resistência em relação à comercialização do ensino superior e ao Ensino à Distância como sua expressão mais manifesta, faz-se necessário pautar estratégias coletivas que garantam a direção ético-política da profissão. A organização da categoria, ainda sustentando seu discurso combatente, não pode deixar de considerar que os profissionais estão se formando a partir de diversas metodologias e espaços, sendo necessário conhecer e traçar ações propositivas para manter o fortalecimento da direção social crítica.

Uma das ações que o CFESS vem desempenhando nesse sentido, ainda que como um pontapé inicial, é a pesquisa sobre perfil dos assistentes sociais na realidade profissional do país e o recadastramento obrigatório (Resolução CFESS Nº 746 DE 22/02/2016). Ainda, temse avanços na implementação da Política de Educação Permanente do Conjunto CFESSCRESS, elaborada em 2012, cujo objetivo é o de promover o:

[...] aprimoramento intelectual, técnico e político dos assistentes sociais como forma de qualificar o exercício profissional, fortalecendo sua inserção qualificada e crítica no mundo do trabalho; bem como consolidar o projeto ético-político do Serviço Social e potencializar a melhoria dos serviços prestados aos USUÁRIOS (CONSELHO FEDERAL DE SERVIÇO SOCIAL, 2012a, p. 28).

O CFESS tem se preocupado também com a pauta do estágio supervisionado em Serviço Social, tendo lançado em 2014 a brochura Meia Formação Não Garante um Direito (CONSELHO FEDERAL DE SERVIÇO SOCIAL, 2014). A partir da identificação de irregularidades sobre credenciamento dos campos de estágio, número de estagiários/as superior por profissional, dificuldades nas garantias éticas e técnicas para o exercício profissional do/a supervisor/a, elaborou esse documento com informações legais e normativas acerca da Supervisão Direta de Estágio em Serviço Social para consulta.

Já a ABEPSS tem desenvolvido o projeto ABEPSS Itinerante, que teve sua primeira edição em 2012, a segunda em 2014 e a última em 2016, realizando oficinas em todos os estados do Brasil na tentativa de consolidar as Diretrizes Curriculares de 1996, no que diz respeito à sua lógica, seus fundamentos e sua direção social.

Todas essas iniciativas, para além de denunciar que a modalidade de ensino à distância não responde às necessidades da formação em Serviço Social, tem contribuído para o fortalecimento da categoria ante os avanços da ofensiva conservadora. Mais importante do que reforçar a dualidade maniqueísta aluno presencial versus aluno EaD, se faz necessário reconhecer as demandas dos sujeitos integrantes dessa modalidade de ensino e transformá-los em aliados na luta contra a precarização, privatização e mercantilização do ensino.

A modalidade do ensino a distância não é uma opção para grande parte dos sujeitos que a integram, sejam alunos ou tutores, mas uma das possíveis oportunidades de ascensão

Temporalis, Brasília (DF), ano 18, n. 36, p. 336-348, jul./dez. 2018. ISSN 2238-1856 


\section{tempordils}

social (como o relatado no primeiro tópico). Geralmente se tem o perfil de alunos trabalhadores, de baixa renda, que vivem em cidades distantes dos grandes polos ou mesmo na zona rural. O desafio é chamar a todos, ainda que submetidos a condições de estudo específicas e limitadas, a lutarem por uma educação pública, laica, presencial e de qualidade.

Mészáros (2008) chama esse movimento de contrainternalização, pois a categoria profissional contraria a imposição de conformidade em relação ao que é posto como dado naturalizado e move-se em direção a um "[...] intercâmbio ativo e efetivo com práticas educacionais mais abrangentes" (MÉSZÁROS, 2008, p. 59). Lutar pela universalização da educação enquanto atividade humana autorealizadora é uma das principais formas de resistência ao conservadorismo no âmbito da formação profissional.

Ainda que a realidade apresente uma grande investida de recursos públicos em universidades privadas, sucateamento das universidades públicas, que dispõem de poucas vagas altamente concorridas num contexto onde a educação básica de qualidade não representa a realidade da maioria dos brasileiros e que os cursos em Serviço Social, em sua maioria, não sejam constituídos pelo tripé ensino, pesquisa e extensão, mantém-se a luta para que todos que querem e precisam se profissionalizar possam ter oportunidades iguais.

\section{Considerações finais}

Ainda que se reconheça a potencialidade emancipadora da educação - quando alinhada a uma perspectiva crítica -, esta tem servido, no mais das vezes, como instrumento de reprodução da ideologia dominante. Exemplo disso pode ser constatado a partir do programa implementado pelo projeto neodesenvolvimentista, ao longo do governo da expresidenta.

Em um breve balanço, identifica-se que a formação para o mercado foi uma das principais características das políticas educacionais nos governos Dilma Rousseff. Não obstante se tenha consolidado a ampliação do acesso à educação superior, o crescimento da oferta (em maior parte pela iniciativa privada) foi priorizado em detrimento da qualidade do ensino.

Uma das principais consequências é o fortalecimento de uma visão que propugna o acesso ao direito à educação pela via concorrencial do mercado. Ignora-se, nesse viés, que a disponibilidade deste como uma mercadoria qualquer, pode repercutir, em épocas de crise econômica, na sua própria negação. Isso pode se dar tanto com a restrição da política pública, como no patamar médio remuneratório da classe trabalhadora, que, uma vez incapaz de comprá-lo, deixará de usufrui-lo.

Especificamente no âmbito da formação superior em Serviço Social, houve uma proliferação dos cursos na modalidade de ensino à distância. Com isso, fragiliza-se os preceitos da direção ético-política da profissão, à medida que a oferta pelas instituições privadas visa estritamente o lucro em detrimento de uma formação humanista com engajamento na perspectiva crítica. Além disso, a profissão prescinde de uma atuação eminentemente coletiva, o que demanda um saber a ser construído desse modo. 
a formação em SERviço social no Período neodesenvolvimentista de dilma roussefF tempor Olif

\section{Referências}

ADORNO, Theodor ; HORKHEIMER, Max. Dialética do esclarecimento. Rio de Janeiro: Zahar, 2006.

ALVES, Giovanni. Trabalho e neodesenvolvimentismo: choque de capitalismo e nova degradação do trabalho no Brasil. Bauru: Canal 6, 2014.

AVRITZER, Leonardo. Impasses da democracia no Brasil. Rio de Janeiro: Civilização Brasileira, 2016.

BOITO JÚNIOR, Armando. Reforma e crise política no Brasil: os conflitos de classe nos governos do PT. Campinas; São Paulo: Unicamp; Unesp, 2018.

BRASIL. Presidência da República. Medida Provisória n 746, de 22 de setembro de 2016. Institui a Política de Fomento à Implementação de Escolas de Ensino Médio em Tempo Integral, altera a Lei $n^{\circ} 9.394$, de 20 de dezembro de 1996, que estabelece as diretrizes e bases da educação nacional, e a Lei ${ }^{\circ} 11.494$ de 20 de junho 2007, que regulamenta o Fundo de Manutenção e Desenvolvimento da Educação Básica e de Valorização dos Profissionais da Educação, e dá outras providências. Diário Oficial da União, República Federativa do Brasil, Brasília (DF), ano CLIII, n.184-A, 23 set. 2016. Disponível em: $<$ http://pesquisa.in.gov.br/imprensa/jsp/visualiza/index.jsp?jornal=1000\&pagina=1\&data=2 3/09/2016>. Acesso em: 26 jun. 2017.

CONSELHO FEDERAL DE SERVIÇO SOCIAL. CFESS manifesta: gestão tempo de luta e resistência (2011-2014). Brasília, DF: CFESS, 2014. Disponível em:

<http://www.cfess.org.br/arquivos/Livro_CFESSManifesta_GestaoTempodeLuta-

Site.pdf $>$. Acesso em: 26 jun. 2017.

CONSELHO FEDERAL DE SERVIÇO SOCIAL. Educação não é fast-food. CFESS [online]. 13 maio 2011. Disponível em: <http://www.cfess.org.br/visualizar/noticia/cod/603>. Acesso em: 28 jun. 2017.

CONSELHO FEDERAL DE SERVIÇO SOCIAL-CONSELHOS REGIONAIS DE SERVIÇO SOCIAL. Política de Educação Permanente do Conjunto CFESS-CRESS. Brasília (DF), $2012 a$.

CONSELHO FEDERAL DE SERVIÇO SOCIAL-CONSELHOS REGIONAIS DE SERVIÇO SOCIAL; ASSOCIAÇÃO BRASILEIRA DE ENSINO E PESQUISA EM SERVIÇO SOCIAL; ENCONTRO NACIONAL ABEPSS; EXECUTIVA NACIONAL DOS ESTUDANTES DE SERVIÇO SOCIAL . Sobre a incompatibilidade entre graduação à distância e serviço social. Brasília (DF), 2012b. Disponível em:

<http://www.cfess.org.br/arquivos/01_sobreaincompatibilidade_2011.pdf>. Acesso em: 27 jun. 2017.

CONSELHO FEDERAL DE SERVIÇO SOCIAL-CONSELHOS REGIONAIS DE SERVIÇO SOCIAL. Sobre a incompatibilidade entre graduação à distância e serviço social. Brasília, DF: CFESS-CRESS, 2015. 1 v. Disponível em: 
<http://www.cfess.org.br/arquivos/incompatibilidadevolume1_2015-Site.pdf>. Acesso em: 27 jun. 2017.

CONSELHO FEDERAL DE SERVIÇO SOCIAL-CONSELHOS REGIONAIS DE SERVIÇO SOCIAL. Sobre a incompatibilidade entre graduação à distância e serviço social. Brasília(DF), 2014. 2 v. Disponível em:

<http://www.cfess.org.br/arquivos/CFESS_incompatibilidadevolume2_2014.pdf>. Acesso em: 27 jun. 2017.

FONSECA, Alana; DIONÍSIO, Bibiana; KANIAK, Thais. Eduardo cunha é condenado a 15 anos de reclusão por três crimes na Lava Jato. G1 [online], seção Paraná RPC, Curitiba, 30 mar. 2017.

FREIXO, Adriano de; RODRIGUES, Thiago (Orgs.). 2016, o ano do Golpe. Rio de Janeiro: Oficina Raquel, 2016.

GRAMSCI, Antonio. Os intelectuais e a organização da cultura. Trad. Carlos Nelson Coutinho. 9. ed. Rio de Janeiro: Civilização Brasileira, 1995.

IAMAMOTO, Marilda Villela. Serviço Social em tempo de capital fetiche: capital financeiro, trabalho e questão social. São Paulo: Cortez, 2007.

IAMAMOTO, M. V.; CARVALHO, R de. Relações sociais e Serviço Social no Brasil: esboço de uma interpretação histórico metodológica. São Paulo: Cortez, 2007.

INSTITUTO NACIONAL DE ESTUDOS E PESQUISAS EDUCACIONAIS. Resumo técnico: Censo da educação superior 2014. Brasília: Instituto Nacional de Estudos e Pesquisas Educacionais, 2016. Disponível em:

<http://download.inep.gov.br/download/superior/censo/2014/resumo_tecnico_censo_edu cacao_superior_2014.pdf>. Acesso em: 26 jul. 2017.

INSTITUTO NACIONAL DE ESTUDOS E PESQUISAS EDUCACIONAIS. Panorama da educação: destaques do Education at a Glance 2015. [S.I.]: Instituto Nacional de Estudos e Pesquisas Educacionais, 2015. Disponível em:

<http://download.inep.gov.br/acoes_internacionais/estatisticas_educacionais/ocde/educa tion_at_a_glance/eag2015_panorama_educacao.pdf >. Acesso em: 26 jul. 2017.

LOPES, Pedro; SEGALLA, Vinícius. Áudios mostram que partidos financiaram MBL em atos pró-impeachment. UOL [online], seção Política, 27 abr. 2016.

MARX, Karl. Sobre a Questão Judaica. São Paulo: Boitempo, 2010.

MEC esclarece que não haverá corte de nenhuma disciplina. Portal do Governo Brasileiro [online], Brasília (DF), 22 set. 2016. Disponível em:

<http://portal.mec.gov.br/component/content/article?id=39581>. Acesso em: 27 jun. 2017.

MÉSZAROS, István. A educação para além do capital. São Paulo: Boitempo, 2008. 


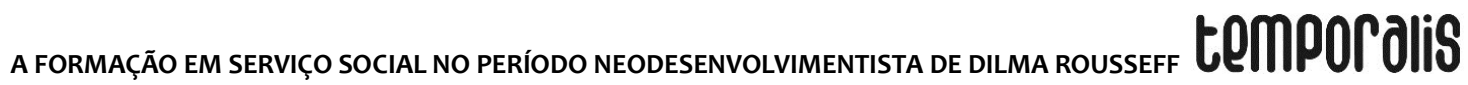

PIRES, Breiller. Brasil despenca 19 posições em ranking de desigualdade social na ONU. EI país [online], São Paulo, 21 mar. 2017. Disponível em:

<http://brasil.elpais.com/brasil/2017/03/21/politica/1490112229_963711.html>. Acesso em: 27 jun. 2017.

SOUZA, João Valdir Alves de. Educação. In: SOUZA, João Valdir Alves de; GUERRA, Rosângela (Orgs.). Dicionário crítico da educação. Belo Horizonte: Dimensão, 2014. 